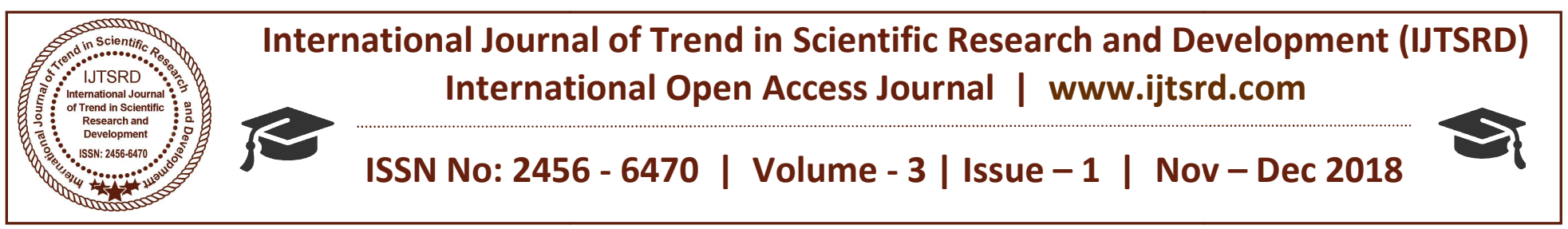

\title{
Investigating in Indigenous Conflict Resolution and Reconciliation Mechanism in Wollo: An Explanation of Abegar from African Solutions (Afsol) Perspective
}

\author{
Mulugeta Tesfaye Teshome \\ Lecturer, Wollo University, Program of Peace and Development Studies, Ethiopia
}

\begin{abstract}
This article introduced the audience about the most known indigenous conflict resolution mechanism in North East Ethiopia called the "Abegar System". "Abegar" is widly practiced in Amhara Region. The Abegar aims at the restoration of order and harmony of the community. Reconciliation is its necessary objective for the restoration of social cohesion of the community in general and of social relationships between conflicting parties in particular. This study is a descriptive in its purpose and case study in its methodological approach. Primary and secondary data are collected for this study. The researcher contributes to create awareness about the issue at hand for concerned body and promote the use of indigenous knowledge as an alternative conflict resolution. The study explored cultural values that contribute to peaceful coexistence, political stability and economic development of the above mentioned community.
\end{abstract}

\section{KEYWORDS: Indigenous, conflict Resolution, Reconciliation, Wollo}

\section{INTRODUCTION}

The term «indigenous» means local or native to the country, the people or the society concerned (Mervyn, 2010). Base on this definition, in this work we can interchangeably use the term "local" and "indigenous" to man home grown or popular in the local community. According to Mervyn (2010), shortly after the beginning of the European colonial adventure, that term gradually assumed a derogatory connotation. In the course of time, it came to be applied exclusively to non-European peoples and [their values], who were, and to some extent, still are considered inferior to those of the Western. That distorted usage of the term has been so systematic and persistent that many people subconsciously came to associate «indigenous / [local] » with «inferior». Regrettably, that dangerous association appears to have influenced our attitudes, our life styles and, more importantly, our choice of development techniques, policies, models, and strategies.

Paul Collier (2007a), suggest that developing states should take context as a starting point to understand the local limits and capacity. It is equivalent to mean local/ indigenous values should be considered as solution to solve local problems. Leaders and policy makers in Africa tried to adopt solutions from foreign countries for many years (Babatunde, \& Mujidat, 2014). On the contrary some African scholars insisted on the need for framing, situating and elevating the discourse on indigenous values to meet pressing security challenges; and by so doing the third world people can mobilize appropriate and timely solutions.

For many centuries like Ethiopian, indigenous knowledge have utilized and practiced in the way that helped the society to exist. These Values are embedded in the culture of the community and are used as first hand solutions to solve their problems. But in the modern Ethiopian history foreign solutions were favored instead of domestic solutions (Assefa, 2011). Despite a long period of this practice, Ethiopia is still facing a number of social, cultural and political problems.

Man works are done on the contribution of indigenous conflict resolution mechanism and and values for being a solution to peace and security problems in Africa. For example Babatunde, Mujidat (2014); Kofi Gbolonyo (2009); Abegunrin (2009); Apuuli (2011); 
Laurie (2013) and George (2010) are some of the scholars that study local indigenous and values and their place in conflict resolution. In Ethiopia the Oromo cultural values particularly Gadaa system and its values are the most explored indigenous institution in Ethiopia from different perspective. For example Asamrom, 1973; Lemmu, 1994; Asafa, 2011; Dirribi, 2011; and Tena, 2013 are some of them. Many other cultural values are less explored issues. Most of the previous works done in the Wollo focused on the issue of religious tolerance and cultural values (Rukya, 2016), conflict resolution mechanisms and the role of traditional institutions like shimgilina, Mesal and sheks (Yasin, 2006; Hassen, 2016; Assefa, 2011). But the present researcher explored the indigenous value of Wollo as alternative solution to solve the prevailing socio-political problems particularly Abegar.

\section{Methods of the Study}

This study is a descriptive in its purpose and case study in its methodological approach. The case study is one type of qualitative research approach that facilitates exploration of a phenomenon within its context using a variety of data sources. Descriptive case study research design provides the opportunity for intensive analysis of many specific details often overlooked by other methods. The researcher used primary and secondary data. The primary data is collected through key informant interview. Secondary data were also collected from different sources like journals, brushers, proclamations, reports from the concerned bodies, court reports/documents, policy documents, and security offices documents. Document review was also the most important data collection instrument. Different published and unpublished documents, journals, farmland conflict related workshop manuals, Brusher, magazines and other key documents which were necessary and related to the study objectives are reviewed to incorporate and enrich the findings of the study.

\section{Result and Discussion}

A number of socio-political problems have continued to threatened peaceful co-existence of people across countries on the continent of Africa more than any other continent in the world (Babatunde, Mujidat (2014). Ethiopia, as part of the continent, shares the same fate. The western model solutions have tried to tackle several socio-political problems in different time by different regimes of African as well as
Ethiopia. But, they have been unable to bring the intended change despite their procedural expediency and philosophical purity.

Volker Boege argued that societies recovering violent conflict need both legal and restorative approaches, addressing different levels and dimensions of truth and justice (Boege, 2006). Many authors suggesting that retributive justice should be complemented with restorative justice. Although this kind of ICRM are important in cases of large-scale human rights violations such as in the former Yugoslavia, Rwanda or Sierra Leone which is impossible to prosecute everyone, there are some ICRM that are designed to use for micro level conflicts.

This essay introduced the audience the most known indigenous conflict resolution mechanism in North East Ethiopia called the "Abegar System". "Abegar" is widly practiced in northern Wollo, northern part of south Wollo Zone, [Oromiya especial Zone of Amhara Region](). The personals are called Abegars. Abegars always care about the security of the society. They teach about peace and love for the people; and they pray for the good of the society. They are considered as the father of peace, the ears and eye of God. In the northern and northern part of Sothern Wollo nobody object the rule of Abegars. Everybody is subject to Abegar rule and the rule is strictly respected if not he/she will be sanctioned by the society. In addition people think that if somebody disappointed Abegar, god will curse the people. For these reasons no one object the proposal of abegar. They are supposed to be fair. For wollo people reconciliation is the virtues act. Abegars, are usually found effective in resolving violent and hidden conflicts, restoration of disputants' relationships, marriage and divorse, stilling, preventing future revenge actions and ensuring peace and security of the local community. As Volker Boege cited in his work "Traditional Approaches to Conflict Transformation - Potentials and Limits" Boraine strongly advocates a holistic interpretation of ICRM based on five key pillars, including accountability, truth recovery, reparations and reconciliation (Boege, 2006). This important pillars of ICRM gives Abegar system acceptance in their community.

Abegars has their Owen territory jurisdiction to adjudicate their law. For example in northern Wollo there are four well known Abegars. In a council of Abegar there are four branches. Main Abegar, 
secretariat, Dereta (executive/ messenger) and Kadami (servants). Abegas may use mosque, shadow of big tree and green field. This is because of symbolization of purity, justice and truth. This helps the negotiation process and trust worthiness. Let, if the person commit a crime the perpetrator went to the house of the Abegar. Or the family of the murderer beg the Abegars for mediation to stop any other death for revenge.

The processes is began with by putting parties together. The call for negotiation done for three time with greater patience and understanding the emotion of victim's family. The executive (dereta) went for calling to the victim's family. It is symbolically done by pivoting a spire on the get of the victim's family. If the family accept the call they put butter on the spire of the dereta. In return, it is believed that they get blessing from the Abegar sprite. Abegars symbolize sitting arrangement too. The Abegars set on higher place in the middle of the victim family and the perpetrators family. It is to symbolize there authority and charisma. On the right victim and perpetrators set to the left to symbolize the bad their shame and their badness. The preparatory family up to three generation needs to demonize themselves. All of the family of perpetrator needs to ware old close, they carry a stone until the family of the victim willing to forgive the perpetrator family. It is to control and reduce the emotional feeling of the victim's family. The audience pray and murmur and even beg for mercy. In this arrangement the negotiation continued.

Conflict is perceived as an unwelcome disturbance of the relationships within the community. Hence, the Abegar aims at the restoration of order and harmony of the community. It is thus geared towards the future. Reconciliation is necessary for the restoration of social harmony of the community in general and of social relationships between conflicting parties in particular. The punishment of Abegar rule is different as the intention of the perpetrator. For example if the perpetrator kill the person intentionally the punishment became strong. The action is called tikur dem/ black blood/. While unintentional murder is called key idem /red blood/. For unintentional act the punishment is considerate. For this act the blood money is half of tikur dem.

Only once a consensus about the facts and the truth has been achieved, perpetrators apologies and ask for forgiveness, and victims can accept the apologies and forgive. Most of the time blood money is given to the victims in the festivity. The importance of this compensation lies in the transformation of reciprocity: the reciprocity of revenge, which is a decisive characteristic of traditional conflicts and which leads into vicious circles of violence, is replaced by the reciprocity of gifts. Conflicts are settled by compensation of a symbolically equivalent amount. After the victim's family became willing to accept negotiation they eat together in one dish and concluded by blessing of the Abegar.

\section{Reference}

1) Abegunrin (2009). Africa in global politics in the twenty-first century: a pan-African perspective. New York: Palgrave, Macmillan.

2) Babatunde, Mojica (2014). The Place of Indigenous Proverbs in Peace Education in Nigeria: Implications for Social Studies Curriculum. International Journal of Humanities and Social Science Vol. 4 No. 2 [Special Issue January 2014].

3) Collier, P (2007a). The Bottom Billion: Why the Poorest Countries Are Failing and What Can Be Done About It, Oxford University Press.

4) Kofi Gbolonyo (2009). Indigenous Knowledge and Cultural Values in Ewe Musical Practice: Their Traditional Roles and Place in Modern Society. PhD Dissertation, University of Pittsburgh.

5) Hassen (2016). Critical Discourse Analysis on Religious Tolerance in South Wollo. Research on Humanities and Social Sciences, Vol.6, No.15.

6) Legesse, Asamrom (1973). Gadaa: Three Approaches to the Study of African Society. NewYork: Free Press.

7) Baissa, Lemmu (1994) Gada Values: The Building Blocks of Democratic Oromo Polity. USA: Journal of Oromo Studies (JOS), Vol. I NO. 2. pp. 17- 52 .

8) Jalata, Asafa (2011). The Oromo in Exile: Creating Knowledge and Promoting Social Justice. Societies without Borders 6 (1), pp. 33 72 Aspects of Oromo Political Culture. Lewis, Herbert. USA: Journal of Oromo Studies, 1994.

9) Demissie, Dirribi(2011). Oromo Wisdom in Black Civilization. Finfinnee, Ethiopia: Finfinne Printing and Publication S.C. 
International Journal of Trend in Scientific Research and Development (IJTSRD) ISSN: 2456-6470

10) Dewo, Tena (2013). The Concept of Peace in the Oromo Gadaa System: Its Mechanisms and Moral Dimension. Finfinne Printing and Publication S.C. Vol. 15.

11) Yasin Mohammed Ali (2006).Traditional Conflict Resolution Mechanism in North East Ethiopia. ISBN 10: $\underline{3846534412}$ / ISBN 13: 9783846534410

12) Rukya Hassen (2016) The Distinctive Features of Menzuma as a Genre of its Own and the
Functions it Serve for the Muslim Community of Wollo: An Ethnographic Approach. Arts Social Science, J 7:190. doi:10.4172/2151-6200.1000190

13) Volker Boege, 2006. Traditional Approaches to Conflict Transformation - Potentials and Limits; Berghof Research Center for Constructive Conflict Management — First Launch Jul.

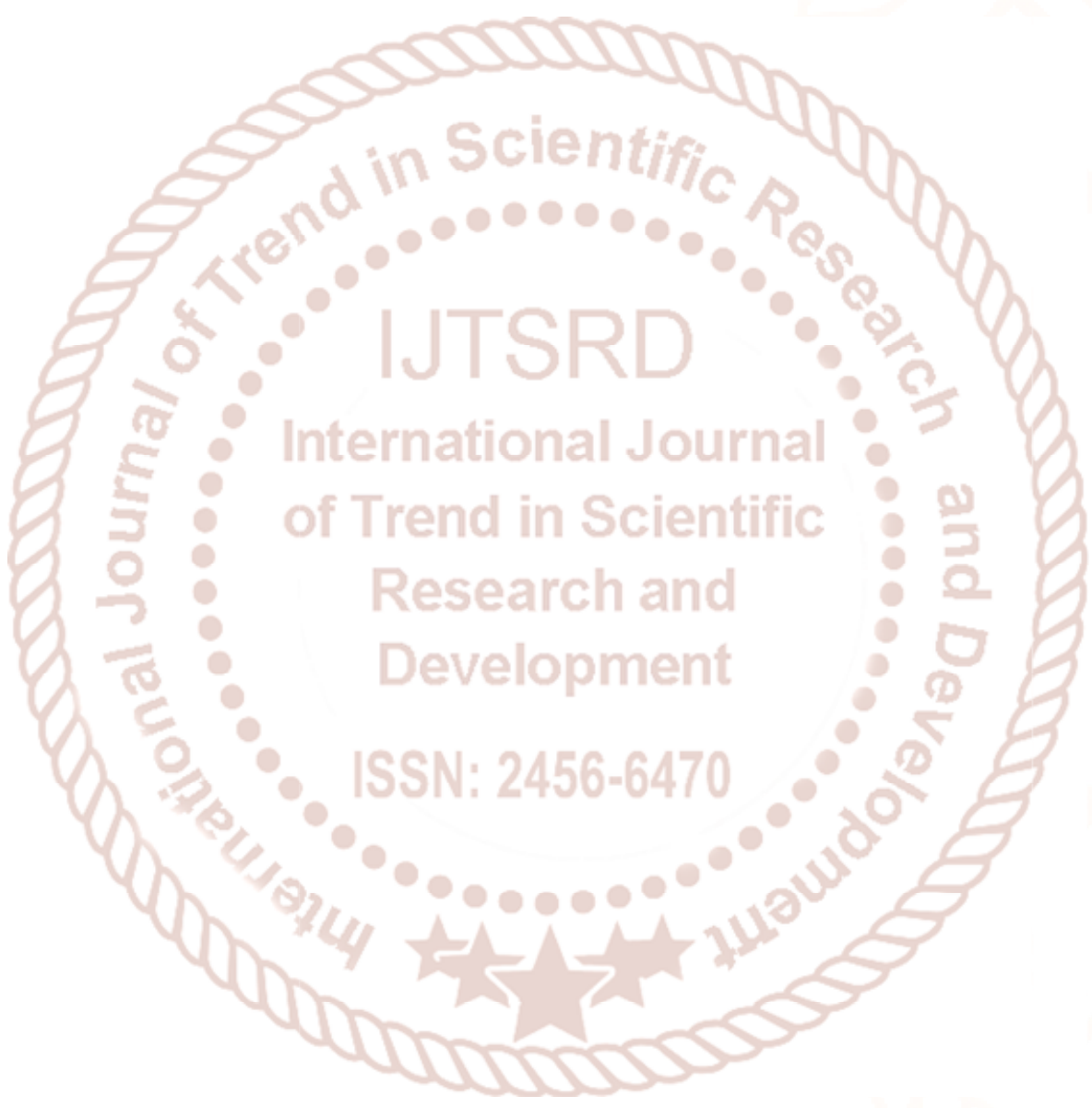

